\title{
STUDI EKSPLORASI PENDIDIKAN KESEHATAN REPRODUKSI ANAK JALANAN DI RUMAH SINGGAH BINAAN PKPR PUSKESMAS JAKARTA TIMUR
}

\section{Exploration Study of Reproductive Health Education among Children at Shelters Under the Program of PKPR in East Jakarta Public Health Centers}

\author{
Faika Rachmawati*, Kenti Friskarini, Lilian Susanti Nova, Hendrik Edison, \\ Rachmalina Prasodjo, Sahat H Manalu \\ Puslitbang Upaya Kesehatan Masyarakat, Badan Litbang Kesehatan, Kementerian Kesehatan RI \\ E-mail: faika_tvi@yahoo.co.id
}

Naskah masuk 19 Februari 2020; review 27 Mei 2020; disetujui terbit 26 Juni 2020

\begin{abstract}
Background: Lack of information and basic knowledge of reproductive health cause street children vulnerable to complex problems, one of which is risky sexual behavior. Reproductive health education is an effort to reduce negative impacts and to protect adolescents from the risk of unwanted pregnancy, abortion, sexually transmitted infections (STIS), HIV/AIDS and sexual violence

Objective: This study aimed to explore the implementation and barriers of reproductive health education among street children at shelters under the program of PKPR in East Jakarta public health centers in DKI Jakarta

Method: This research used qualitative methods. Data were collected by in-depth interviews. There were 20 research informants consisting of program stakeholders for street children and school-aged children health program at the central level, health offices, social services, public health centers, managers of shelters and street children assisted by shelters in East Jakarta.

Results: Knowledge of reproductive health among street children was still poor. The implementation of reproductive health education carried out by PKPR in public health centers was still not optimal because it has not reached all street children at the shelter as well as the lack of trained health resources implementing PKPR trained.

Conclusion: Efforts are needed to optimize reproductive health education among street children by strengthening commitment and building networks
\end{abstract}

Keywords: reproductive health education, knowledge, PKPR, street children

\begin{abstract}
Abstrak
Latar belakang: Kurangnya informasi dan pengetahuan dasar mengenai kesehatan reproduksi menyebabkan anak jalanan rentan terhadap permasalahan yang kompleks, salah satunya adalah perilaku seks berisiko. Pendidikan kesehatan reproduksi merupakan salah satu cara untuk mengurangi dampak negatif serta melindungi remaja dari risiko kehamilan yang tidak dikehendaki, aborsi, Infeksi Menular Seksual (IMS), HIV/AIDS dan kekerasan seksual.

Tujuan: Penelitian ini bertujuan untuk menggali pelaksanaan dan hambatan pendidikan kesehatan reproduksi pada anak jalanan di rumah singgah binaan PKPR puskesmas wilayah Jakarta Timur di DKI Jakarta

Metode: Penelitian ini menggunakan metode kualitatif. Data dikumpulkan dengan wawancara mendalam. Informan penelitian berjumlah 20 orang yang terdiri dari pemegang program anak jalanan dan kesehatan usia remaja dan sekolah di tingkat pusat, Dinas Kesehatan, Dinas Sosial, puskesmas, pengelola rumah singgah dan anak jalanan binaan rumah singgah di Jakarta Timur.

Hasil: Pengetahuan anak jalanan tentang kesehatan reproduksi masih kurang. Pelaksanaan pendidikan kesehatan reproduksi yang dilakukan melalui program PKPR puskesmas masih belum maksimal karena belum menjangkau seluruh anak jalanan di rumah singgah serta kurangnya SDM kesehatan pelaksana PKPR yang terlatih.

Kesimpulan: Diperlukan upaya untuk memaksimalkan pendidikan kesehatan reproduksi pada anak jalanan dengan memperkuat komitmen dan membangun jejaring
\end{abstract}

Kata kunci: pendidikan kesehatan reproduksi, pengetahuan, PKPR, anak jalanan 


\section{PENDAHULUAN}

Persoalan anak jalanan tidak pernah ada habishabisnya. Ibarat pepatah "patah tumbuh hilang berganti" yang dapat menjadi gambaran betapa sulitnya mengatasi masalah ini. Bukan hanya peningkatan jumlah anak jalanan, namun termasuk masalah kesehatan yang mengikuti fenomena ini, karena anak jalanan merupakan kelompok yang rentan. Anak jalanan ini membutuhkan perhatian dan pelayanan kesehatan khusus, termasuk menerima informasi tentang kesehatan yang benar melalui pendidikan kesehatan. Pendidikan kesehatan penting dilakukan karena untuk menumbuhkan perilaku kesehatan jauh lebih baik dilakukan selama kanak- kanak daripada mencoba merubah perilaku tersebut pada masa dewasa. ${ }^{1}$ Data jumlah anak jalanan merupakan data yang dinamis dan tidak tetap karena anak jalanan terbiasa memiliki mobilitas yang tinggi sehingga tidak ada angka yang pasti. Walaupun begitu, data anak jalanan sangat penting untuk mengatasi masalah terutama dalam pemenuhan hak anak. Hal ini sangat membutuhkan perhatian baik dari pemerintah, LSM dan masyarakat umum.

Jika dipelajari dari beberapa hasil survei di beberapa negara berkembang, dapat diketahui bahwa jumlah anak jalanan diketahui bertambah setiap hari. ${ }^{2,4}$ The United Nations International Children's Emergency Fund (UNICEF) memperkirakan bahwa jumlah anak-anak dan pemuda yang tinggal di jalanan berkisar dari sepuluh hingga ratusan juta. ${ }^{5}$ Berdasarkan data laporan Program Kesejahteraan Sosial Anak ( PKSA) dari Kementerian Sosial pada tahun 2015, jumlah anak jalanan menunjukkan bahwa dari 2,9 juta anak terlantar, terdapat 34.400 anak jalanan ${ }^{6}$, dengan remaja usia 14-18 tahun merupakan bagian terbesar dari kelompok anak jalanan. ${ }^{7}$

Remaja yang merupakan bagian terbesar dari kelompok anak jalanan ini memiliki risiko masalah kesehatan yaitu kebiasaan merokok, menggunakan narkotika, psikotropika dan zat

\footnotetext{
*Korespondensi: faika_tvi@yahoo.co.id

(C) Badan Penelitian dan Pengembangan Kesehatan ISSN: 2354-8762 (elektronik); ISSN: 2087-703X (cetak)
}

adiktif lainnya (NAPZA), perilaku seks bebas dan masalah kesehatan reproduksi seperti Infeksi Menular Seksual (IMS) dan HIV/AIDS. WHO menyebutkan 1 dari 20 remaja tertular IMS setiap tahunnya dikarenakan kehidupan seksual dan reproduktif remaja yang berisiko serta kurangnya pemahaman dan pengetahuan mereka mengenai risiko yang ditimbulkan akibat dari perilaku seksual. ${ }^{8}$ Sebuah penelitian di Yogyakarta menyebutkan bahwa perilaku seks bebas pada anak jalanan dapat menimbulkan IMS yang disebabkan bergantiganti pasangan, tidak memperhatikan kebersihan diri dan lingkungan. Sebagian besar anak jalanan tidak menggunakan alat kontrasepsi ketika berhubungan seks, sehingga berdampak pada penularan infeksi menular seksual (IMS) dan kehamilan yang tidak diinginkan. ${ }^{9}$ Menurut laporan Sistem Informasi HIV AIDS dan IMS (SIHA) oleh Ditjen Pengendalian Penyakit dan Pengendalian Lingkungan Kemenkes RI, diketahui bahwa jumlah kumulatif penderita HIV AIDS dan IMS semakin meningkat. Pada tahun 2016 diketahui bahwa penderita HIV sebesar 1.510 kasus pada kelompok umur 15-19 tahun dan mengalami peningkatan pada tahun 2017 menjadi 48.300 kasus. $^{10}$

Perilaku seksual remaja cenderung menunjukkan sikap yang permisif terhadap perilaku seks bebas atau seks di luar nikah. Sikap permisif remaja terhadap perilaku seks bebas didukung oleh terbatasnya pengetahuan tentang kesehatan reproduksi remaja. Hasil Survei Dasar Kesehatan Indonesia (SDKI) tahun 2017 menyatakan bahwa pengetahuan remaja tentang kesehatan reproduksi belum memadai hanya 33 persen remaja perempuan dan 37 persen remaja laki-laki dengan usia 1524 tahun mengetahui kemungkinan lebih besar untuk hamil apabila berhubungan seksual. Tingkat pengetahuan remaja berupa pemahaman mengenai gejala IMS menunjukkan bahwa sebesar 61 persen laki-laki dan 65 persen perempuan tidak mengetahui gejala IMS. 
Hal-hal tersebut di atas menunjukkan pentingnya pendidikan untuk mencegah terjadinya masalah kesehatan reproduksi. ${ }^{11}$ Rendahnya pengetahuan remaja tersebut berdampak pada perilaku seksual remaja kearah perilaku seksual yang berisiko.

Kementerian Kesehatan telah melaksanakan berbagai program kesehatan anak yang diarahkan pada pemenuhan hak dan perlindungan anak melalui intervensi program sesuai dengan sasaran yang memang bervariasi baik jenis maupun strategi dalam memberikan pelayanan kesehatan. Karena usia remaja memiliki proporsi terbesar pada kelompok anak jalanan, sehingga pelayanan kesehatan remaja merujuk pada program Pelayanan Kesehatan Peduli Remaja (PKPR) di puskesmas. Sasaran pengguna layanan PKPR adalah seluruh remaja usia 10 - 19 tahun dan berarti termasuk di dalamnya adalah kelompok anak jalanan di rumah singgah. Dinas Sosial juga memiliki program yang memperhatikan kesejahteraan anak jalanan yaitu PKSA. Kedua kegiatan tersebut mempunyai tujuan yang sama yaitu untuk menjamin kesejahteraan anak termasuk anak jalanan sehingga keduanya seharusnya bersinergi untuk mencapainya.

Tulisan ini mengangkat hasil dari penelitian yang bertujuan untuk menggali pendidikan kesehatan reproduksi pada anak jalanan di rumah singgah binaan PKPR puskesmas wilayah Jakarta Timur di DKI Jakarta pada tahun 2017 dengan menggali permasalahan atau hambatan pelaksanaan pendidikan kesehatan reproduksi yang sudah ada, sehingga mendapatkan gambaran serta kebutuhan tentang pendidikan kesehatan reproduksi untuk anak.

\section{METODE}

Penelitian ini menggunakan metode kualitatif yang dikumpulkan dengan wawancara mendalam. Penelitian dilaksanakan di DKI Jakarta wilayah Kota Jakarta Timur. Puskesmas dan rumah singgah dipilih secara purposif dari yang tercatat di Dinas Kesehatan Provinsi yaitu dua puskesmas yang sudah melaksanakan layanan PKPR (Pelayanan Kesehatan Peduli Remaja) dan mempunyai binaan anak jalanan di rumah singgah yaitu Puskesmas Kramat Jati dan Puskesmas Jatinegara, dengan rumah singgah binaannya yaitu rumah singgah Akur Kurnia dan rumah singgah Erka. Kecamatan Jatinegara dan Kecamatan Kramat Jati merupakan daerah penyumbang jumlah anak jalanan yang cukup signifikan di wilayah Jakarta Timur. Penelitian ini dilaksanakan pada bulan Juli hingga Oktober tahun 2017, dengan mendapatkan persetujuan etik dari Komisi Etik Penelitian Kesehatan Balitbangkes nomor LB.02.01/2/KE.233/2017.

Informan dalam penelitian ini berjumlah 20 orang yang terdiri dari delapan orang yang terdiri dari pemegang program anak jalanan dan kesehatan keluarga usia remaja dan sekolah di tingkat pusat, dinas kesehatan, dinas sosial, puskesmas, pengelola rumah singgah dan anak jalanan binaan rumah singgah di Jakarta Timur serta 12 orang anak jalanan binaan rumah singgah Akur Kurnia dan Erka. Pengambilan informan anak jalanan dilakukan secara purposive sampling dilanjutkan dengan snowball sampling berdasarkan pertimbangan anak jalanan yang dipandang dapat memberikan informasi secara maksimal. Informan anak jalanan mewakili kelompok umur 10-19 tahun sesuai dengan kriteria remaja menurut WHO.

Anak jalanan yang terpilih menjadi informan terdiri dari anak jalanan laki- laki dan perempuan. Pengumpulan data dilakukan dengan cara wawancara mendalam dan observasi. Alat bantu yang digunakan dalam pengumpulan data adalah panduan wawancara mendalam dengan pertanyaan berbentuk tidak terstruktur dan terbuka, observasi atau pengamatan serta alat perekam. Selain itu dilakukan penelusuran data sekunder antara lain kebijakan, Rencana Usulan Kegiatan (RUK)/ Rencana Pelaksanaan Kegiatan (RPK) puskesmas, hasil laporan program PKPR, serta tinjauan kepustakaan. Analisis data dilakukan mulai dari transkrip, reduksi data, penelusuran tema, penyajian data hingga uji keabsahan data dengan menggunakan teknik triangulasi data.

\section{HASIL}

Pendidikan kesehatan reproduksi remaja pada anak jalanan di DKI Jakarta dilakukan melalui program PKPR puskesmas. Berbagai risiko yang dapat terjadi jika anak jalanan tidak menjadi penerima program layanan kesehatan 
reproduksi meliputi kerentanan untuk mengalami gangguan kesehatan reproduksi seperti kehamilan usia muda, aborsi, penyakit akibat hubungan seksual (IMS dan HIV). Melihat latar belakang tersebut maka perlu diketahui bagaimana anak jalanan mendapatkan program layanan kesehatan reproduksi. Kementerian Kesehatan RI telah mengembangkan program kesehatan remaja yang dituangkan dalam buku pedoman pelayanan kesehatan anak jalanan dengan pendekatan Pelayanan Kesehatan Peduli Remaja (PKPR) sebagai salah satu bentuk strategi dan kegiatan pelayanan kesehatan kepada anak jalanan.

"Sebetulnya bukunya kan ada dari
jaman 2014 itu sudah kita buat. Bahwa
pendekatannya nggak berbeda seperti
yang sekarang pelayanan itu
mendorong mereka ke puskesmas
memperkenalkan tentang PKPR dan
dorong mereka untuk datang tempat
PKPR" (LND, 51 tahun, informan
Kementerian Kesehatan)

Kegiatan pendidikan kesehatan remaja di puskesmas menunjukkan bahwa ketersediaan program pendidikan kesehatan reproduksi untuk remaja sudah tersedia melalui PKPR puskesmas seperti di wilayah Jakarta Timur namun belum spesifik menargetkan pada anak jalanan sebagai penerima layanan. Layanan PKPR di puskesmas terdiri dari layanan konseling, penyuluhan kesehatan reproduksi, dan layanan pemeriksaan kesehatan reproduksi untuk remaja usia 15-24 tahun dan semua usia pada anak jalanan. Meskipun demikian dalam pelaksanaannya PKPR puskesmas membina panti sosial yang menaungi anak jalanan bukan rumah singgah.

"Justru kan puskesmas ini membinanya adalah membina panti bukan rumah singgah. panti itu kan ada pengurusnya ada bangunannya ada SK nya ada pembiayaannnya" (LND, 51 tahun, informan Kementerian Kesehatan)

"Kemitraan dengan puskesmas ...panti panti nya itu mereka sudah berbuat MoU ya kalo ngga salah...” (DWN, 37 tahun, informan Dinkes Jakarta Timur)
Hal ini disebabkan rumah singgah tidak memiliki struktur yang jelas, baik dari perijinan maupun pembiayaannya, sehingga puskesmas membina panti dalam menjaga kesehatan anakanak yang ada di dalamnya. Kemitraan rumah singgah dengan puskesmas dilakukan dengan inisiatif pengelola rumah singgah untuk melaporkan keberadaan rumah singgah di wilayah kerja puskesmas.

"Sebenernya ada rumah singgah yang lain tapi yang dibina puskesmas cuma satu, Tidak ada yang melapor lagi..."

(AND, 39 tahun, informan Puskesmas Jatinegara)

Pelaksanaan kegiatan PKPR luar gedung salah satunya adalah skrining kesehatan, yang melibatkan tim berbagai program di puskesmas yang terdiri dari tenaga pelaksana gizi, dokter umum dan dokter gigi, pelaksana program promosi kesehatan dan PKPR. Hal ini dilakukan karena efisiensi waktu, anggaran tetapi juga sumber daya manusia (SDM). Puskesmas Kramat Jati melakukan skrining kesehatan pada anak jalanan di rumah singgah Akur Kurnia minimal satu kali dalam setahun, sedangkan Puskesmas Jatinegara belum pernah melakukan skrining kesehatan pada anak jalanan. Pelaksanaan skrining kesehatan yang dilakukan oleh Puskesmas Kramat Jati pun kepada anak jalanan bukan merupakan hal yang mudah, selain harus melibatkan banyak program di puskesmas, puskesmas perlu memberikan cendera mata kepada anak jalanan sebagai daya tarik mereka datang pada saat skrining, seperti alat kebersihan diri sabun, pasta gigi, gunting kuku, baju, buku bekas, makanan kecil dan minuman yang merupakan sumbangan dari staf puskesmas, agar dapat menjaring anak jalanan lebih banyak.

Pelaksanaan pendidikan kesehatan pada anak jalanan di rumah singgah dilakukan oleh Puskesmas Kramat Jati dan Puskesmas Jatinegara. Puskesmas Kramat Jati melakukan kegiatan tersebut bersamaan pada waktu pelaksanaan kegiatan skrining kesehatan. Materi pendidikan kesehatan reproduksi yang sering diberikan saat pembinaan dari puskesmas lebih sering tentang pengetahuan tentang HIV/AIDS dan PHBS, sedangkan materi yang berkaitan dengan pengetahuan tentang sistem reproduksi dan pengalaman pubertas, meliputi perubahan fisik pada masa 
pubertas, masa subur dan risiko kehamilan dan pemeriksaan kesehatan sebelum menikah belum disampaikan.

"Kita berikan pengetahuan terkait
penyakit penyakit menular yang potensi
$e$ bisa menyerang anak jalanan
termasuk HIV/AIDS ...pengetahuan
kesehatan reproduksi belum." (AND,
39 tahun, informan Puskesmas
Jatinegara)
"Pertama itu biasanya tentang apa
PHBS...dengan HIV IMS." (JWT, 43
tahun, informan Puskesmas Kramat
Jati)

Selain kegiatan luar gedung, pendidikan kesehatan yang diberikan oleh puskesmas dalam gedung melalui layanan konseling yang merupakan salah satu bagian kegiatan PKPR. Namun sayangnya masih belum ada anak jalanan di rumah singgah mengetahui dan memanfaatkan adanya layanan konseling. Sebagian besar anak jalanan yang memanfaatkan layanan konseling adalah remaja anak sekolah. Pelayanan konseling di puskesmas masih kurang terbuka karena menunggu rujukan dari poli umum atau poli KIA/KB apabila ditemukan kasus seperti, hamil pada usia dini, atau penyakit IMS yang terjadi pada remaja. Berikut adalah kutipan wawancara dengan pengelola tentang hal tersebut.

\begin{abstract}
"Nah mereka belom apa ya.. belom familiar dengan konseling itu belum kalo dengan kita dengan puskesmas ya..sejauh ini kemungkinan anak sekolah yang mengakses..." (JWT, 43 tahun, informan Puskesmas Kramat Jati)
\end{abstract}

Puskesmas sudah berupaya melakukan pendidikan kesehatan melalui kegiatan PKPR dalam dan luar gedung, namun masih banyak permasalahan yang timbul saat pelaksanaan kegiatan yang berhubungan dengan pada anak jalanan. Petugas kesehatan setidaknya membutuhkan waktu untuk pendekatan. Hal ini disebabkan adanya kecurigaan dan ketakutan dari anak jalanan apabila melihat petugas yang berseragam, bahwa mereka akan diangkut oleh petugas dan di bawa ke lembaga sosial.
“... terus rupanya pendekatan disitu dia kan agak- agak takut ya karna sebenernya kan butuh waktu khusus kan untuk konseling apalagi pake seragam kan bisa marah mereka kan..." (DWN, 37 tahun, informan Dinkes Jakarta Timur)

Selain itu, jumlah anak jalanan yang mengikuti kegiatan tersebut masih dibatasi, sehingga informasi yang disampaikan tidak menjangkau seluruh anak jalanan di rumah singgah tersebut. Sehingga sebagian besar informan anak jalanan belum memahami tentang kesehatan reproduksi, karena mereka tidak mengikuti penyuluhan dan masih terbatasnya informasi tentang kesehatan reproduksi masih terbatas. Dari hasil penelitian diketahui juga bahwa sebagian besar informan anak jalanan tidak pernah mendapatkan pendidikan kesehatan reproduksi berupa penyuluhan dari puskesmas.

\section{"Tidak pernah ikut penyuluhan" (TMI, 15 tahun, laki-laki, informan anak jalanan rumah singgah Akur Kurnia)}

"Gak tau” (FRZ, 14 tahun, laki-laki, informan anak jalanan rumah singgah Akur Kurnia)

Menurut sebagian besar informan anak jalanan yang diwawancarai tidak mudah untuk menjelaskan masalah-masalah kesehatan reproduksi karena mereka tidak terbiasa untuk menceritakan masalah kesehatan reproduksi mereka. Malu dan takut adalah perasaan yang dominan yang mereka rasakan untuk mengungkapkan rasa sakit atau hal-hal terkait dengan kesehatan reproduksi. Pembicaraan tentang kesehatan reproduksi dan kesehatan seksual masih merupakan hal yang tabu sehingga mereka tidak paham kepada siapa mereka seharusnya berbicara, termasuk petugas kesehatan yang telah dikenalnya. Informan anak jalanan belum memahami bahwa perilaku mereka berpeluang lebih besar terpapar narkoba, kehamilan yang tidak direncanakan, penularan IMS dan HIV baik penularan melalui hubungan seks maupun penggunaan NAPZA. Mereka bahkan tidak menyadari risiko tersebut dan bahkan tidak mengetahui apa yang sebenarnya disebut kesehatan reproduksi. Informasi terkait dengan masalah kesehatan reproduksi yang dialami mereka pun tidak 
selalu mendapatkan jawaban yang dibutuhkan. Selain itu, mereka tidak tahu akan berobat dimana jika sakit ataupun informasi tempattempat penyedia layanan pengobatan yang tepat untuk anak jalanan. Hal ini diketahui salah satunya dari kutipan informan di bawah ini.

\section{"Itu abang pernah bilang, kalau sakit kelamin yang periksa saja... tapi gak tau periksa kemana" (HDI, 14 tahun, laki-laki, informan anak jalanan rumah singgah Akur Kurnia)}

Sebagian anak jalanan yang dekat dengan lokasi puskesmas atau anak jalanan yang pernah mengikuti kegiatan yang diselenggarakan oleh puskesmas, cukup terpapar dengan informasi layanan yang tersedia atau layanan penyedia lainnya. Namun sebagian anak jalanan lainnya mengobati sendiri jika mengalami rasa sakit pada alat kelamin dengan membeli obat gatal di warung atau toko obat. Mereka mengutarakan rasa sakit yang mereka alami ke penjual obat hingga mendapatkan salep. Karena tidak ada informasi tentang cara penggunaan obat dan kondisi jika rasa gatal hilang atau sakit lainnya hilang, mereka menghentikan pengobatan mereka sendiri. Hal ini menunjukkan ketidaktahuan anak jalanan akan layanan kesehatan yang tersedia di puskesmas ataupun layanan lainnya yang bisa diakses oleh anak jalanan termasuk kesehatan reproduksi.

Selain itu cara penyampaian materi pendidikan kesehatan pada anak jalanan tidak bisa disamakan dengan anak sekolah. Anak jalanan mempunyai karakteristik yang berbeda dibandingkan dengan anak sekolah. Penyampaian kesehatan reproduksi diharapkan menggunakan bahasa yang dimengerti oleh anak jalanan karena sebagian besar anak jalanan belum bisa membaca dan menulis. Beberapa informan anak jalanan menginginkan bentuk kegiatan pendidikan kesehatan melalui penanyangan film, diskusi dan gambar.

Informan pengelola rumah singgah membenarkan anak jalanan binaan rumah singgah nya pernah memanfaatkan PKPR dari puskesmas, namun pelaksanaannya masih bersifat menunggu. Informan dari salah satu rumah singgah yaitu rumah singgah Erka di wilayah kerja Puskesmas Jatinegara menyampaikan bahwa kegiatan pendidikan kesehatan reproduksi pada anak jalanan sudah ada sejak tahun 1999, dengan bantuan pihak swasta sebagai lembaga donornya. Pelaksanaan nya juga dengan jumlah anak yang terbatas, dengan harapan dari anak yang sudah mendapatkan ilmu tersebut bisa mempengaruhi teman sebayanya yang lain. Pernyataan yang sama diungkapkan juga oleh informan pengelola rumah singgah Akur Kurnia bahwa kegiatan pendidikan kesehatan tentang kesehatan reproduksi dilakukan tidak hanya oleh puskesmas namun juga oleh swasta. Informan mengakui adanya koordinasi yang cukup baik antara rumah singgah dengan penanggung jawab pemegang program PKPR Puskesmas. Informan tersebut juga menyebutkan pendidikan tentang kesehatan reproduksi pernah mereka dapatkan dari puskesmas namun tidak rutin setiap tahun. Mereka justru sering mendapatkan pendidikan kesehatan reproduksi dengan metode penyuluhan dari Lembaga Swadaya Masyarakat (LSM) dan iniversitas. Jawaban berbeda diberikan oleh anak jalanan yang menyatakan bahwa sebagian besar mereka tidak pernah mendapatkan penyuluhan kesehatan reproduksi dari puskesmas. Hal tersebut disebabkan karena anak jalanan mempunyai karakteristik dinamis yang datang dan pergi sehingga seringkali pada saat kegiatan pendidikan kesehatan reproduksi, yang hadir bukan anak yang sama lagi.

Di samping itu, kurangnya SDM yang terlatih menjadi salah satu faktor tidak berjalannya pendidikan kesehatan reproduksi pada anak jalanan. Hal ini disebabkan karena luasnya cakupan anak jalanan di DKI Jakarta. Kegiatan pendidikan kesehatan reproduksi masih dilakukan di sekolah dan panti sosial milik pemerintah.

“...Saya di bagian PKPR ini untuk ke panti saya belom... Belom maksimal gitu lho.. Kemudian saya sedang intens nya ini ke anak sekolah. [...] Ya kalo menurut saya ya kalo untuk menjangkau anak jalanan ini memang butuh tenaga yang benar benar extra [...] Gitu kan karena tadi di kemenkes sudah ngga ada lagi namanya pelatihan gitu kan nah di dinas sudah tidak ada lagi." (DWN, 37 tahun, informan Dinkes Jakarta Timur) 
Konselor sebaya merupakan salah satu solusi agar pendidikan kesehatan bisa tersampaikan pada teman anak jalanan lainnya. Namun konselor sebaya yang dilatih oleh puskesmas masih dalam lingkungan sekolah dan belum menjangkau anak jalanan di rumah singgah. Sedangkan informan pengelola rumah singgah Erka mengatakan bahwa pelatihan konselor sebaya pernah dilakukan dengan dana swadaya dan LSM.

“... pelatihan via edukator apa via
edukatoryang TOT itu kitanggadiadakan
disini kita nyewa hotel dengan budget
yang ada dari lembaga donor itu ataupun
LSM nyewa aula lah itu tapi kalo kita
ngadain dengan biaya sendiri...” (HRM,
$\mathbf{4 4}$ tahun, informan rumah singgah
Erka)

Kesejahteraan anak jalanan juga merupakan bagian dari tugas Dinas Sosial. Sesuai penjelasan informan yang berasal dari Dinas Sosial, diketahui bahwa Dinas Sosial mempunyai program dan kegiatan terkait anak jalanan yaitu PKSA. Program ini dirancang sebagai upaya yang dilakukan pemerintah dalam bentuk pelayanan dan bantuan kesejahteraan sosial anak jalanan yang meliputi bantuan sosial/subsidi pemenuhan kebutuhan dasar, peningkatan aksesibilitas terhadap pelayanan sosial dasar (akte kelahiran, pendidikan, kesehatan, tempat tinggal dan air bersih, rekreasi, keterampilan dan lain-lain), penguatan dan tanggung jawab orangtua/ keluarga dalam pengasuhan dan perlindungan anak, penguatan kelembagaan kesejahteraan sosial anak, namun belum menjangkau rumah singgah. ${ }^{12}$ Bantuan untuk pembinaan di rumah singgah masih berupa rekomendasi dari Dinas Sosial. Yang dimaksud dengan memberikan rekomendasi adalah apabila ada rumah singgah yang membutuhkan bantuan operasional atau untuk mendapatkan kartu sehat.

Dinas Sosial sendiri tidak mempunyai kebijakan khusus yang berhubungan dengan kesehatan reproduksi remaja. Dinas Sosial tidak melaksanakan kegiatan yang berhubungan dengan pendidikan dan pelayanan kesehatan reproduksi anak jalanan karena bukan bagian dari pekerjaan Dinas Sosial. Selain itu Dinas Sosial tidak memiliki anggaran untuk kegiatan tersebut. Untuk mengatasi masalah kesehatan anak jalanan Dinas Sosial dan Kementerian Kesehatan membuat kesepakatan. Kesepakatan tersebut dibuat agar anak jalanan mendapatkan surat rekomendasi dari Dinas Sosial dan Dinas Kependudukan jika ingin mendapatkan pelayanan kesehatan. Surat rekomendasi dibuat agar anak jalanan mendapatkan kartu sehat dan dapat gratis di puskesmas. Berdasarkan pengakuan informan di atas, tidak semua anak jalanan di rumah singgah telah terdata. Hal ini dapat terjadi karena sebagian besar anak jalanan tidak memiliki identitas seperti KTP dan kartu BPJS. Permasalahan kesehatan yang terjadi pada anak jalanan di rumah singgah tidak pernah diketahui atau dilaporkan ke Dinas Sosial, sehingga Dinas Sosial tidak mempunyai data terkait dengan masalah kesehatan anak jalanan di rumah singgah.

\section{"Ya mungkin lebih apa ya lebih menonjol lagi terkait dengan permasalahan permasalahan kaya tadi di situ sendiri permasalahan terkait dengan kesehatan tadi rumah singgah itu sendiri gitu karena untuk selama ini ya permasalahan terkait dengan kesehatan belom sampai ke kita..." (MSK, 36 tahun, informan Dinas Sosial)}

"Harapannya ya ada kegiatan seperti ini promosi kesehatan untuk setiap tahun ada gitu ya karena ini memang penting soal nya masalah nya terkait dengan anakanak jalanan...." (MSK, 36 tahun, informan Dinas Sosial Jakarta Timur)

\section{PEMBAHASAN}

Hasil SDKI tahun 2012 menunjukkan bahwa pengetahuan remaja tentang kesehatan reproduksi belum memadai. Hanya 35,3 persen remaja perempuan dan 31,2 persen remaja lakilaki berusia 15-19 tahun yang mengetahui perempuan dapat hamil dengan satu kali berhubungan seksual. Tingkat pengetahuan remaja laki-laki berupa pemahaman mengenai gejala IMS pada laki-laki 16,4 persen dan pada perempuan 6,1 persen, sedangkan tingkat pengetahuan remaja perempuan berupa pemahaman mengenai gejala IMS yang terjadi pada laki-laki 15,8 persen dan pada perempuan 15,3 persen. ${ }^{13}$ Sementara itu, hasil SDKI tahun 
2017 menyatakan bahwa kesehatan reproduksi bahwa pengetahuan remaja tentang kesehatan reproduksi belum memadai yaitu hanya 33 persen remaja perempuan dan 37 persen remaja laki-laki berusia 15-24 tahun yang mengetahui kehamilan kemungkinan lebih besar dapat terjadi apabila berhubungan seksual. Sementara itu, 61 persen remaja tidak mengetahui gejala IMS pada laki-laki dan 65 persen remaja tidak mengetahui gejala IMS pada perempuan. ${ }^{11} \mathrm{Hal}-$ hal tersebut di atas menunjukkan pentingnya pendidikan dengan cara penyuluhan kesehatan untuk mencegah terjadinya masalah kesehatan reproduksi.

Gaya hidup anak jalanan lebih berisiko terhadap masalah kesehatan, seperti dalam tinjauan literature pada 16 negara di Afrika ditemukan bahwa anak laki-laki lebih banyak hidup dijalanan daripada anak perempuan. Adanya intervensi kesehatan pada anak jalanan dapat meningkatkan status kesehatan anak jalanan termasuk penyediaan tempat berlindung yang aman, nutrisi yang tepat, akses ke pelayanan kesehatan, pendidikan kesehatan, dan kesehatan reproduksi seksual, perlindungan dari segala bentuk pelecehan, kekerasan dan penyalahgunaan zat aditif. ${ }^{14}$

Pendidikan kesehatan reproduksi sudah saatnya diberikan kepada remaja, baik melalui pendidikan formal maupun informal. Tujuannya antara lain untuk memberikan pengetahuan, mencegah anak jalanan dari perilaku seksual berisiko dan perilaku berisiko lainnya yang dapat berpengaruh terhadap kesehatan reproduksi, menurunkan tingkat kematian dan kesakitan remaja saat ini, mengurangi beban penyakit di masa yang akan datang, menumbuhkan remaja menjadi pribadi yang sehat dan bertanggung jawab baik pada saat ini maupun di masa depan, memenuhi hak manusia dan melindungi produktivitas remaja. ${ }^{15,16}$ Hal tersebut penting untuk mencegah bias pada pendidikan kesehatan reproduksi maupun pendidikan tentang seks di kalangan remaja, khususnya anak jalanan. Era globalisasi dan keterbukaan informasi, misalnya internet membuat segala bentuk informasi menjadi sangat mudah didapat. Sayangnya sangat sulit untuk membendung informasi yang dapat merusak kepribadian remaja, misalnya pornografi dan kehidupan seksual bebas adalah hal yang sangat sulit. Selain itu, orang tua, lingkungan dan juga institusi pendidikan, tampaknya belum siap untuk menghadapi kemajuan teknologi informasi yang berkembang dengan sangat cepat.

Kemudahan memperoleh pengetahuan yang kurang tepat mengenai seks mempengaruhi sikap anak jalanan terhadap hubungan seksual. Selain itu perilaku remaja sering mengarah kepada perilaku yang berisiko, seperti penyalahgunaan NAPZA, perilaku yang memudahkan terkena infeksi HIV/AIDS, dan IMS, karena perilaku seksual yang tidak sesuai dengan norma-norma yang berlaku seperti berganti-ganti pasangan atau aborsi yang tidak aman. Dengan demikian bentuk pendidikan kesehatan harus disesuaikan dengan kondisi anak jalanan, seperti yang disebutkan dalam penelitian Vitriani yang diketahui bahwa terdapat pengaruh nilai yang didapatkan dari lingkungan terhadap perilaku kesehatan anak jalanan sehingga dibutuhkan pendidikan kesehatan secara terprogram menggunakan karakter yang sesuai dengan anak jalanan, misalnya kegiatan penyuluhan yang tidak terlalu formal dengan suasana yang santai dan kekeluargaan. ${ }^{17}$

Beberapa pihak termasuk yayasan telah mencoba menolong anak jalanan dan mengatasi permasalahan anak jalanan agar kembali hidup secara normatif melalui pemberdayaan anak jalanan salah satunya melalui rumah singgah. Rumah singgah merupakan suatu wahana yang dipersiapkan sebagai perantara antara anak jalanan dengan pihak yang akan membantu mereka dalam berkegiatan. Dengan kata lain, penanganan masalah anak jalanan dilakukan melalui rumah singgah. Berdasarkan pedoman penyelenggaraan pembinaan anak jalanan melalui rumah singgah Kementerian Sosial RI, rumah singgah didefinisikan sebagai perantara anak jalanan dengan pihak-pihak yang akan membantu mereka. Rumah singgah merupakan proses informal yang memberikan suasana pusat realisasi anak jalanan terhadap sistem nilai dan norma di masyarakat serta merupakan tahap awal bagi anak jalanan untuk memperoleh pelayanan selanjutnya. ${ }^{18}$

Pedoman pelaksanaan kegiatan pada anak jalanan salah satunya diterapkan melalui program PKPR di puskesmas. PKPR merupakan pelayanan kesehatan yang ditujukan dan dapat dijangkau oleh remaja, 
bersifat menyenangkan, menerima remaja dengan tangan terbuka, menghargai remaja, menjaga kerahasiaan, peka akan kebutuhan terkait dengan kesehatannya, serta efektif dan efisien dalam memenuhi kebutuhan remaja. PKPR dilaksanakan baik di dalam gedung maupun di luar gedung. ${ }^{19}$ Program pendidikan kesehatan reproduksi untuk remaja sudah tersedia melalui program PKPR di puskesmas namun dari hasil wawancara mendalam diketahui bahwa program tersebut belum spesifik dalam menargetkan pada anak jalanan sebagai penerima layanan. Seperti hasil penelitian Iram Barida dkk yang menyebutkan bahwa implementasi kegiatan PKPR di luar gedung dilakukan di sekolah di wilayah kerja puskesmas. ${ }^{21}$ Salah satu alasan tidak terjangkaunya kegiatan pendidikan kesehatan reproduksi pada anak jalanan disebabkan karena tidak semua anak jalanan di rumah singgah terdata dan sebagian besar anak jalanan tidak memiliki identitas seperti KTP dan kartu BPJS. Walaupun begitu anak jalanan masih mendapatkan kesempatan menerima program layanan berupa PKPR lainnya, seperti pemeriksaan IMS dan HIV namun pelaksanaannya bersifat menunggu, sementara untuk pelayanan kesehatan masih bisa didapatkan secara gratis di puskesmas dengan membawa buku berobat atau diantarkan langsung oleh pengelola rumah singgah. ${ }^{20}$

Permasalahan ini tentu masih menjadi pekerjaan rumah bagi sektor terkait karena masih belum memenuhi hak anak seperti yang tertera dalam Undang Undang RI Nomor 4 Tahun 1979 tentang Kesejahteraan Anak, yang mengatur tentang kesejahteraan anak, usia anak, hak anak termasuk hak anak yang tidak mempunyai orang tua, anak yang tidak mampu, anak yang mengalami masalah kelakuan, dan anak cacat. Undang-undang ini juga mengatur tentang tanggung jawab orang tua terhadap kesejahteraan anak dan usaha kesejahteraan anak.Konvensi Hak Anak (KHA) ini ditetapkan melalui Keputusan Presiden RI Nomor 36/1990 pada 25 Agustus 1990. ${ }^{21}$

Secara rinci, implementasi KHA, di Indonesia ditandai dengan lahirnya Undang-Undang Nomor 23 Tahun 2002 Tanggal 22 Oktober 2002 tentang Perlindungan Anak. Sebagai tindak lanjut dari kebijakan tersebut dibentuk "Komisi Perlindungan Anak Indonesia" (KPAI), yang “independen" (Pasal 74 UU PA).
Hak anak dalam KHA meliputi: "hak sipil dan kebebasan fundamental, hak kesehatan, gizi, air dan sanitasi lingkungan, hak lingkungan keluarga dan perawatan alternatif, hak pendidikan, waktu bersantai dan bermain serta kegiatan budaya, dan hak perlindungan khusus". Dalam hal ini, anak adalah sebagai pemangku hak yang bertanggung jawab dalam bertindak dan menyatakan hak-hak mereka; dan negara adalah pengemban tugas yang bertanggung jawab dalam bertindak dan memenuhi/ melindungi/menghormati hak-hak pemangku hak. Dalam undang-undang ini dijelaskan pula peran keluarga yaitu: "keluarga paling berkewajiban mengakui dan memenuhi hak-hak anak, keluarga berada pada posisi sentral dan utama dalam memberikan perlindungan pada anak, serta keluarga adalah lingkungan terdekat bagi anak dan keluargalah yang paling mengenali kebutuhan dan kondisi anak" (Pasal 26 Undang-Undang Nomor 23 Tahun 2002); peran masyarakat yaitu: "masyarakat berhak memperoleh kesempatan seluas luasnya untuk berperan dalam perlindungan anak, peran masyarakat dilakukan oleh orang perseorangan, lembaga perlindungan anak, lembaga sosial kemasyarakatan, lembaga swadaya masyarakat, lembaga pendidikan, lembaga keagamaan, badan usaha, dan media massa agar dilaksanakan sesuai dengan ketentuan peraturan perundang-undangan yang berlaku" (Pasal 72 Undang-Undang Nomor 23 Tahun 2002); dan peran pemerintah yaitu: "bertanggung jawab atas pelaksanaan tahapan pada aspek legislatif, administratif, dan lainnya dengan memaksimalkan sumber yang ada, bertanggung jawab dalam hal pembuatan laporan kepada PBB dan masyarakat, dan bertanggung jawab untuk melakukan diseminasi KHA baik kepada semua pihak termasuk anak-anak". ${ }^{22}$

Melihat ketentuan-ketentuan di atas, pemenuhan hak anak jalanan untuk memperoleh identitas dan terjaminnya kesehatan mereka tentu memerlukan kerjasama dan dukungan dari sektor terkait lainnya. Salah satunya, kerjasama berupa kesepakatan antara Dinas Sosial dan Dinas Kesehatan untuk melaksanakan salah satu pendidikan kesehatan. Hal ini merupakan kegiatan yang dapat dilakukan untuk mendukung revitalisasi penanganan anak jalanan melalui rumah singgah. Kerjasama dengan Dinas Sosial terkait 
dengan data rumah singgah dan jumlah anak jalanan perlu dilakukan. Data tersebut dapat dipergunakan apabila ada kegiatan program puskesmas salah satunya PKPR, yang dapat melibatkan anak jalanan di rumah singgah. Selain itu, pada saat pelaksanaan kegiatan promosi kesehatan reproduksi sebaiknya mengikutsertakan Dinas Sosial dan LSM. Kurangnya SDM dalam program promosi kesehatan reproduksi melalui PKPR, dapat diatasi melalui bekerjasama dengan LSM, akademisi atau lembaga sosial lainnya yang peduli dengan anak jalanan. ${ }^{23,24}$

Pesan dan strategi yang dikembangkan untuk merespon masalah kesehatan reproduksi dapat dilaksanakan melalui penguatan kegiatan atau layanan yang diselenggarakan oleh rumah singgah dan puskesmas dengan dukungan dari Dinas Sosial dan Dinas Kesehatan Provinsi DKI Jakarta. Penting untuk mengutamakan pelayanan kepada anak jalanan mulai dari promosi dan pencegahan, perawatan, dukungan dan pengobatan. Untuk mengembangkan model intervensi kesehatan reproduksi pada anak jalanan maka kerangka berpikir yang digunakan adalah fungsi pokok program yang mencakup penilaian, pengembangan kebijakan dan penjaminan kualitas bagi anak jalanan. Ketiga fungsi pokok ini akan memberikan arahan dan dasar bagi pelaksanaan kegiatan atau layanan di dalam intervensi yang dikembangkan agar mampu laksana yaitu menghasilkan kinerja (aksesibilitas, cakupan, kualitas, dan keberlangsungan) sehingga mampu hasil yang berupa perubahanperubahan yang diharapkan oleh intervensi yang bersangkutan.

\section{KESIMPULAN}

Dari hasil dan pembahasan di atas diketahui bahwa pendidikan kesehatan reproduksi kepada anak jalanan sudah berjalan melalui pendekatan PKPR di puskesmas, namun masih kurang maksimal. Permasalahan dan hambatan pelaksanaan pendidikan kesehatan reproduksi terjadi sejak dari penyedia layanan hingga penerima layanan yaitu anak jalanan di rumah singgah. Adapun permasalahan dalam pendidikan kesehatan reproduksi antara lain, penyuluhan tentang kesehatan reproduksi, layanan konseling yang belum menjangkau seluruh anak jalanan di ruang lingkup rumah singgah dan masih mengutamakan remaja di sekolah dan panti sosial milik pemerintah, kurangnya SDM kesehatan pelaksana PKPR yang terlatih, serta minimnya anggaran yang di alokasikan untuk remaja di luar sekolah salah satunya anak jalanan, serta tidak berjalannya sosialisasi yang melibatkan pemangku kepentingan dan kelompok masyarakat. Selain permasalahan itu, permasalahan lain meliputi konselor sebaya (peer educator) yang dilatih masih dalam lingkungan sekolah dan belum menjangkau anak jalanan di rumah singgah, kurangnya fasilitas kesehatan terkait pelaksanaan pendidikan kesehatan reproduksi seperti alat bantu audio-visual, leaflet, poster dan lain-lain serta kesenjangan informasi pada anak jalanan di rumah singgah sehingga diperlukan langkah-langkah yang lebih konkrit dan berkesinambungan dalam pendidikan kesehatan reproduksi yang bertujuan meningkatkan perlindungan kesehatan untuk anak jalanan.

Pesan dan strategi yang dikembangkan untuk merespon masalah kesehatan reproduksi dapat dilaksanakan melalui penguatan kegiatan atau layanan yang diselenggarakan oleh rumah singgah dan puskesmas dengan dukungan dari Dinas Sosial dan Dinas Kesehatan Provinsi DKI Jakarta. Untuk mengembangkan model intervensi kesehatan reproduksi pada anak jalanan maka kerangka berpikir yang digunakan adalah fungsi pokok program yang mencakup penilaian, pengembangan kebijakan dan penjaminan kualitas bagi anak jalanan. Ketiga fungsi pokok ini akan memberikan arahan dan dasar bagi pelaksanaan kegiatan atau layanan di dalam intervensi yang dikembangkan agar mampu laksana yaitu menghasilkan kinerja (aksesibilitas, cakupan, kualitas, dan keberlangsungan) yang diharapkan.

\section{SARAN}

Penelitian lebih lanjut pada anak jalanan perlu dilakukan untuk mengetahui pengetahuan, sikap dan perilaku tentang pendidikan kesehatan reproduksi. Penyelenggaraan kegiatan pendidikan kesehatan reproduksi kepada anak jalanan perlu dilakukan secara terencana, terarah dan berkesinambungan dengan memperluas cakupan sasaran pada anak jalanan yang didukung sarana dan prasarana 
seperti SDM terlatih, anggaran yang memuat program kreatif tentang peningkatan kualitas kesehatan anak jalanan serta alat bantu audio visual baik berupa media cetak, maupun media elektronik yang memenuhi selera dan kebutuhan anak jalanan. Kesediaan dan komitmen dari puskesmas dan rumah singgah juga sangat penting untuk meningkatkan kualitas program pendidikan kesehatan reproduksi pada anak jalanan dengan dukungan dari Dinas Sosial dan Dinas Kesehatan dari Provinsi DKI Jakarta. Direktorat Kesehatan Keluarga Kementerian Kesehatan diharapkan dapat memodifikasi program yang selama ini digunakan untuk memberikan pelayanan kepada remaja dengan mengintegrasikan upaya memberikan pelayanan kesehatan reproduksi kepada anak jalanan secara lebih spesifik. Sosialisasi perlu melibatkan semua pihak yang berhubungan dengan kesehatan remaja dengan membangun jejaring dalam penyediaan dan pemanfaatan program PKPR antara anak jalanan, kelompok masyarakat, lintas program, lintas sektor dan LSM.

\section{UCAPAN TERIMA KASIH}

Kami mengucapkan terima kasih kepada Sekretariat Balitbangkes Kemenkes yang telah membiayai penelitian Riset Pembinaan Kesehatan ini. Kami juga berterima kasih kepada Dr. dr. Julianti Pradono, MS dan Sri Irianti, SKM, M.Phil., PhD sebagai pembina peneliti yang telah memberikan masukan dan saran perbaikan dalam penelitian ini. Ucapan terima kasih kami sampaikan pula kepada PPH Unika Atmajaya, Dinas Kesehatan Provinsi DKI Jakarta, Dinas Sosial Jakarta Timur, Puskesmas Kramat Jati Jakarta Timur, Puskesmas Jatinegara Jakarta Timur, rumah singgah Akur Kurnia, rumah singgah Erka dan pihak lainnya yang tidak bisa kami sebutkan satu persatu yang telah membantu pelaksanaan penelitian ini sehingga dapat terlaksana dengan baik dan lancar.

\section{DAFTAR PUSTAKA}

1. Allensworth D, Lewallen TC, Stevenson B, Katz S. Addressing the needs of the whole child: What public health can do to answer the education sector's call for a stronger partnership. Prev Chronic Dis. 2011;8(2).
2. Povian CM, Architecture F, Street TL. New Trends and Issues Proceedings on Humanities New Learning Environments for Street Children. Sel Pap 6th World Conf Learn Teach Educ Leadersh (Wclta 2015) 29-31 Oct 2015, Descartes Univ Paris, Fr New. 2016;8(8):19-24.

3. Hakim MA, Rahman A. Health and Nutritional Condition of Street Children of Dhaka City: An Empirical Study in Bangladesh.

Http://WwwSciencepublishinggroupCom. 2015;4(1):6.

4. Amalia M, Krisnani H, Irfan M. Pelayanan Sosial Bagi Anak Jalanan Ditinjau Dari Perspektif Pekerjaan Sosial. Soc Work J. 2014;4(2).

5. Mentari P, Daulima NHC. Hubungan Pola Asuh Orangtua Dan Harga Diri Anak Jalanan Usia Remaja. J Keperawatan Indones. 2017;20(3):158-67.

6. Suryani, Hardiati E. Peran Sakti Peksos dalam Pendampingan Program

Kesejahteraan Sosial Anak. J PKS. 2016;65-76.

7. Kemenkes RI. Profil Kesehatan Indonesia 2018 [Indonesia Health Profile 2018]. 2019.

8. Pandjaitan MC, Niode NJ, Suling PL. Gambaran Pengetahuan dan Sikap Terhadap Infeksi Menular Seksual pada Remaja di SMA Frater Don Bosco Manado. e-CliniC. 2017;5(2).

9. Riyatno A, Isnaeni Y. Hubungan Tingkat Pengetahuan Kesehatan Reproduksi dengan Perilaku Anak Jalanan yang telah melakukan Seks Bebas di Kota Yogyakarta. Naskah Publ Progr Stud Ilmu Keperawatan Fak Ilmu Kesehat Univ Aisiyah Yogyakarta. 2019;

10. Kementrian Kesehatan RI. General situation of HIV/AIDS and HIV test. Pusat Data dan Informasi Kementrian Kesehatan RI. 2018.

11. BKKBN, BPS, Kemenkes RI. Survei Demografi Kesehatan Indonesia. Usaid. 2018.

12. Putri YA, Mulyana N, Resnawaty R. Program Kesejahteraan Sosial Anak(PKSA) Dalam Memenuhi 
Kesejahteraan Anak Jalanan. In: Prosiding Penelitian dan Pengabdian kepada Masyarakat. 2015. p. 57-61.

13. Badan Pusat Statistik, Badan Koordinasi Keluarga Berencanan Nasional, Departemen Kesehatan, Macro International. Survei Demografi dan Kesehatan Indonesia 2012. Sdki. 2013;16.

14. Qudsyi H. Program Peer Education sebagai Media Alternatif Pendidikan Kesehatan Reproduksi Remaja di Indonesia. In: Proceeding Seminar Nasional "Selamatkan Generasi Bangsa dengan Memberntuk Karakter Berbasis Kearifan Lokal" Jilid 2. 2015. p. 111-4.

15. Uyun Z. Peran Orang Tua Dalam Pendidikan Kesehatan Reproduksi. Pros Semin Nas Parent 2013 Sos. 2013;356372:37-9.

16. Lala H. Evaluasi Program Kesehatan Reproduksi Remaja "DAKU!" (Dunia Remajaku Seru) di SMU. JPS (Jurnal Pendidik Sains). 2015;3(2):90-7.

17. Vitriani E, Suryani D. Perilaku Hidup Bersih dan Sehat (PHBS) pada Anak Jalanan di Yayasan Rumah Impian
Yogyakarta. J Berk Kesehat. 2019;5(2):45.

18. Kementerian Sosial RI, Direktorat Jenderal Rehabilitasi Sosial DKSA. Pedoman Operasional PKS-Anak Jalanan 2013.

19. Kementerian Kesehatan RI. Pedoman Standar Nasional Pelayanan Kesehatan Peduli Remaja ( PKPR ). 2014. 1 p.

20. Barida I, Nurmansyah MI, Sabilla M. An Evaluation of Youth Care Health Program (PKPR) in Public Health Center in Jakarta, Indonesia. Proc 1st Int Conf Soc Determ Heal Cent Jakarta, Indones. 2019; (January 2018):56-60.

21. UU RI No. 4 Tahun 1979 Tentang Kesejahteraan Anak. 1979.

22. Undang-Undang RI No.23 Tahun 2002 Tentang Perlindungan Anak. 2002.

23. Suyatna H. Revitalisasi Model Penanganan Anak Jalanan di Rumah Singgah. JSP J Ilmu Sos dan Ilmu Polit. 2011;15(1):41-54.

24. Susilowati D. Kebijakan Penanggulangan Anak Jalanan di Kota Malang. In: Seminar Nasional dan Gelar Produk 17-18 Oktober. 2017. p. 884-9. 